\title{
LA MANO IZQUIERDA Y LA MANO DERECHA DEL ESTADO*
}

R.P.Droit; T.Ferenczi: Un reciente número de la revista que usted dirige tiene como tema el sufrimiento. ${ }^{40}$ Allí encontramos varias entrevistas a gente que los medios de comunicación no les han concedido la palabra: jóvenes de las afueras de la ciudad, desheredados, pequeños agricultores, trabajadores sociales. El rector de un colegio en crisis explica, por ejemplo, su amargura personal: en vez de continuar su transmisión de conocimientos, se ha opuesto a su propio status, convirtiéndose en una especie de policía. ¿Piensa usted que tales testimonios individuales anecdóticos permiten comprender un malestar colectivo?

Pierre Bourdieu: En la encuesta que nosotros levantamos sobre el sufrimiento social encontramos mucha gente que, como el rector del colegio, se siente afectada por las contradicciones del mundo social, vividas en forma de dramas personales. Yo podría citar, por ejemplo, el caso de un jefe de proyecto encargado de coordinar todas las acciones de un barrio marginal en una pequeña ciudad al norte de Francia. Él estaba enfrentando las contradicciones que ese extremo geográfico padece con los llamados "trabajos sociales": asistentes sociales, educadores, magistrados y también, algunas veces, profesores y maestros. Ellos conforman algo que yo llamo la mano izquierda del Estado; es decir, un conjunto de agentes que dependen de los ministerios del Estado central. Se oponen al Estado de la mano derecha, esto es, a los anarcos del Ministerio de Finanzas, de los bancos públicos o privados y de los gabinetes ministeriales. Varios movimientos sociales con los cuales colaboramos (y seguiremos colaborando) elaboran una revuelta de la pequeña nobleza de Estado contra la gran nobleza de Estado.

\section{R.P.D.;T.F.: ¿Cómo explica usted esta inconformidad, y sus estrategias de revuelta?}

P.B.: Yo pienso que la mano izquierda que el Estado tiene cree que la mano derecha no sabe nada o peor, que no quiere saber lo que está haciendo la mano izquierda. En todo caso, que no quiere pagar el precio de esto. Una de las mayores justificaciones para el desespero de la gente radica en el hecho de que el Estado se haya retirado, o esté por hacerlo, de un cierto número de sectores de la vida social que le incumben y que, por lo tanto, debe asumir: el arriendo público, la televisión, la radio y la escuela pública, los hospitales públicos, etc., conducta escandalosa, al menos para quienes de un Estado socialista se debería esperar, por lo menos, que garantice el servicio público como un servicio verdaderamente abierto para todos, sin ningún tipo de distinción. Lo que hemos caracterizado como una crisis de lo político, un antiparlamentarismo, es en realidad el desespero que produce el Estado en tanto responsable del interés público.

Que los socialistas no hayan conseguido lo que en nombre del socialismo pretenden hacer, no podría ofuscar a nadie: los tiempos son duros y el margen de maniobrabilidad es mínimo. Pero lo que realmente sí resulta sorprendente es que hayan contribuido a tal punto en la disminución de la cosa pública: al comienzo, por medio de toda clase de medidas o políticas (en esta ocasión solamente nombraré los medios de comunicación) que apuntaban a la liquidación de las adquisiciones del Welfare State (Estado de

\footnotetext{
* Entrevista con R. P Droit et T. Ferenczi, publicada en Le Monde, el 14 de enero de 1992. Traducción de E Sanabria y G. Vargas.

40 "La souffrance", Actes de la Recherche en Sciences Sociales, 90, diciembre de 1991, y P Bourdieu et al., La Misare du Monde, Paris, Éditions Du Seuil, 1993.
} 
bienestar) y sobre todo, quizá, a través del discurso público que exalta la empresa privada (como si el espíritu de empresa no tuviera otro terreno que el de la empresa) y aviva el interés privado. Todo esto resulta un poco sorprendente, especialmente para quienes han sido comisionados en primera instancia para satisfacer esas funciones "sociales", para suplir las insuficiencias menos tolerables de la lógica del mercado, sin los medios necesarios para cumplir exitosamente sus misiones. ¿Cómo no sentir que habían sido reprobados de entrada?

Debimos haber entendido, después de tanto tiempo, que esas revueltas iban más allá de los problemas de salario, aun cuando el salario otorgado es un índice inequívoco del bajo valor acordado al trabajo y a los trabajadores responsables. El menosprecio de una función se siente desde el comienzo por la irrisoria remuneración que le es acordada.

R.P.D.; T.F.: ¿Cree usted que el margen de maniobra para los dirigentes políticos sea realmente así de restringido?

P.B.: Sin duda, pienso que este margen es mucho menor que lo que uno quisiera creer. Sin embargo, existe un área en la que los gobernantes están a sus anchas: es el caso de lo simbólico.

El carácter ejemplar de la conducta debe imponerse a todos los trabajadores del Estado, sobre todo cuando se considera heredero de una tradición consagrada a los intereses de los más desprovistos. Entonces, ¿cómo no cuestionarse no solamente ante los casos de corrupción (que algunas veces casi alcanzan a ser oficiales, como la irregularidad de las primas de ciertos altos funcionarios), o por la traición al servicio público y todas las formas de malversación de fondos con fines privados, de los bienes, beneficios y servicios públicos: nepotismo, favoritismo (nuestros dirigentes tienen muchos amigos personales”...), clientelismo? ¡Y ni hablar de las ganancias simbólicas!

La televisión ha contribuido, sin duda, tanto como los barriles de vino, a la degradación de las virtudes civiles: con la convocatoria y puesta sobre la escena política e intelectual el "¿y tú, me has visto?", intentando ante todo hacer ver y valer todo lo opuesto a los valores de respeto hacia el interés colectivo. Este mismo tipo de egoísmo del hacer valer (seguidamente a expensas de los rivales), explica cómo los "efectos de anuncio» se han transformado en un interés común. Todo parece indicar que para muchos ministros, una medida no se realiza si no puede ser anunciada y dada por hecha desde su misma publicación. En resumen, la enorme corrupción genera escándalo porque revela la diferencia entre las virtudes profesadas y las prácticas reales, que no es más que el límite de todas las pequeñas "debilidades" ordinarias, como las demostraciones de lujo, y las aprobaciones apresuradas de privilegios materiales o simbólicos.

R.P.D.; T.E: ¿Para hacer frente a la situación que usted describe, cuál debería ser, en su opinión, la reacción de los ciudadanos?

P.B.: Hace poco leí un artículo de un escritor alemán sobre el antiguo Egipto; ahí muestra cómo, en una época de crisis de confianza hacia el Estado y los bienes públicos, surgían dos tipos de reacciones, a saber: en los dirigentes, la corrupción, correlativa al declinar el respeto hacia los asuntos públicos; y en los dominados, la religiosidad personal, asociada al desespero respecto a los recursos personales.

De la misma manera, hoy se cree que el ciudadano se siente excluido del Estado (que en el fondo no exige nada fuera de las contribuciones materiales obligatorias, y sobre 
todo, ningún sacrificio ni entusiasmo), entonces lo rechaza, considerándolo como un poder extranjero que se aprovecha de sus mejores recursos.

R.P.D.; T.F.: Usted hablaba del gran poder de los gobiernos en la esfera simbólica. Esto no implica solamente las conductas ejemplares. Son también palabras, ideales movilizadores. En este sentido, ¿de dónde proviene la deficiencia actual?

P.B.: Se ha hablado mucho del silencio de los intelectuales, pero lo que me golpea realmente es el silencio de los políticos. Ellos sí que están formidablemente desprovistos de ideales movilizadores. No cabe duda de que la profesionalización de la política y que las condiciones exigidas a quienes quieren hacer carrera dentro de los distintos partidos, agotan cada vez más a las personalidades inspiradas. Tampoco dudo de que la definición de la actividad política ha cambiado desde la llegada del personal formado en las escuelas (de Ciencia Política), qué con toda la seriedad posible o simplemente para evitar parecer azuzadoras, prefieren hablar de gestión antes que de autogestión, y de la necesidad, en todos los casos, de legitimar las apariencias (a través del lenguaje) de la racionalidad económica.

Encerrados por una economía estrecha y asociados a la nueva visión del mundo (FMI) que hace (y hará) también estragos en las relaciones norte-sur, todos los medio capacitados en materia de economía olvidan, evidentemente, los costos reales a corto y sobre todo a largo plazo de la miseria material y moral, verdadera consecuencia de una Realpolitik económicamente legitimada: delincuencia, criminalidad, alcoholismo, accidentes de ruta, etc. Aquí, la mano derecha, aún obsesionada por el asunto de los equilibrios financieros, ignora lo que hace la mano izquierda, que siempre enfrenta las consecuencias sociales de las "economías presupuestarias", por lo general demasiado costosas.

R.P.D.; T.F: ¿Podrían tener más credibilidad los valores que fundamentan los actos y las contribuciones del Estado?

P.B.: Quienes hacen de guardianes del Estado son los primeros en burlar su propia credibilidad: el congreso de Rennes y la ley de amnistía han aumentado el descrédito del socialismo mucho más que los diez años de campaña antisocialista; un militante volteado (en todo el sentido de la palabra) genera más estragos que diez adversarios. En efecto, los diez años de poder socialista han terminado derrumbando la fe en el Estado y, por consiguiente, han destruido el Estado-providencia, empresa de los años setenta realizada en nombre del liberalismo. Pienso en particular en la política de arrendamiento: ésta tenía por principio declarado expulsar a la pequeña burguesía del espacio colectivo (en nombre del "colectivismo"), y entonces limitar la propiedad privada a sus viviendas. Ahora bien, actualmente esta política no cumple sus propios principios, los resultados ilustran lo que ya dije sobre los costos sociales para ciertas economías, $y$, además, se ha convertido, indudablemente, en la mayor causa de la segregación espacial y, por lo mismo, de los problemas en los barrios marginales.

R.P.D.; T.F.: Si quisiéramos definir un ideal, éste sería la recuperación del sentido del Estado y de los asuntos públicos. ¿Compartiría usted esta opinión de todo el mundo?

P.B.: La opinión de todo el mundo, ¿es la opinión de quién? De las personas que escriben en lo periódicos, de los intelectuales que predican por el "menos Estado" y que entierran precipitadamente el interés público por lo público.., se tiene un ejemplo típico de 
este efecto de creencia compartida que pone repentinamente fuera de discusión a ciertas tesis claramente discutibles.

Sería necesario analizar el trabajo colectivo de los "nuevos intelectuales" que han creado un clima favorable para el retiro del Estado y, con mayor razón, a propósito de los valores en economía. Pienso en lo que ha sido llamado "el retorno del individualismo": es como una especie de profecía autorrealizante que tiende a destruir los fundamentos filosóficos del Welfare State (Estado de bienestar), y en particular, la noción de responsabilidad colectiva (en el accidente de trabajo, la enfermedad o la miseria), conquista fundamental del pensamiento social (y sociológico). El retorno del individuo es algo que también permite "censurar a la víctima", en tanto que único responsable de su infelicidad, y predicar la política del self help (sálvese quien pueda), todo esto bajo el manto de la necesidad incansablemente repetida de disminuir los costos de la empresa.

La reacción de pánico retrospectivo que ha ocasionado la crisis del 68 , revolución simbólica que sacudió a todos los pequeños portadores de un capital cultural, ha creado (con y reforzado por el hundimiento — ¡inesperado! — de los regímenes de tipo soviético) las condiciones necesarias para la restauración cultural, de manera que "el pensamiento Sciences-Po (científico-político)" ha reemplazado "el pensamiento maoísta". El mundo intelectual es, en este momento, el lugar de una lucha destinada a producir e imponer "nuevos intelectuales", de ahí las nuevas definiciones del intelectual y de su papel político, de la filosofía y del filósofo, acordes con los vaporosos debates de una filosofía política sin técnica, de una ciencia social reducida a una politología del ser real electoral, y de un comentario sin vigilancia de sondeos comerciales sin método. Platón tenía una palabra magnífica para todas éstas personas: doxosophe, que significa "técnico de la opinión que se cree sabio" (he traducido el triple sentido de la palabra), que pone los problemas de la política en los mismos términos que los hombres de negocios, los hombres políticos y los periodistas políticos (es decir, exactamente aquellos que pueden costear los sondeos...).

R.P.D.; T.R: Usted acaba de nombrar a Platón. La aptitud del sociólogo, ¿se aproxima a la del filósofo?

P.B: EL sociólogo se opone a la doxosophe. Como el filósofo, pone en tela de juicio las cosas dadas como evidentes, sobre todo aquellas que se presentan en forma de preguntas, tanto las suyas como las de los demás. Es esto lo que choca profundamente al doxosophe, que cree ver un prejuicio político en el rechazo a la sumisión profundamente política que implica la aceptación inconsciente de los lugares comunes, como decía Aristóteles: esas nociones o tesis con las cuales se argumenta, pero sobre las cuales no se argumenta.

R.P.D.; T.F.: ¿No cree que usted tiende a poner al sociólogo en el lugar de un filósoforey, que sólo así puede determinar dónde están los verdaderos problemas?

P.B.: Lo que yo defiendo, ante todo, es la posibilidad y la necesidad del intelectual crítico, y crítico, en principio, de la doxa intelectual que secretan los doxosophes. No puede haber una verdadera democracia sin un verdadero contrapoder crítico, y esto depende del intelectual, que somos nosotros, y de primera clase. Por esto considero que el trabajo de demolición del intelectual crítico, esté muerto o vivo -Marx, Nietzsche, Sartre, Foucault, y los etiquetados como Pensée 68 (el pensamiento del 68)—, es tan peligroso como la demolición de la cuestión pública, y se inscribe dentro de la misma empresa global de restauración. 
Me gustaría más que los intelectuales, todos, y todo el tiempo, estuvieran a la altura de la inmensa responsabilidad histórica que les corresponde, y que lo hagan siempre trabajando con acciones; es decir, no sólo con su autoridad moral, sino también con su competencia intelectual, a la manera de un Pierre Vidal-Naquet, que ha aplicado toda su maestría del método histórico a una crítica de los abusos de la historia ${ }^{41}$. En cierta forma, estoy de acuerdo con lo que dice Karl Kraus: "si tengo que escoger el menor entre dos males, no escojo ninguno". Así pues, sí casi no tengo casi indulgencias por los intelectuales "irresponsables", preferiría tener menos indulgencias por los responsables "intelectuales", polígrafos poliformes, que ponderan su entrega anual entre dos consejos de administración, tres cócteles de prensa y algunas apariciones en televisión.

R.P.D.; T.F.: ¿Entonces, qué papel desearía usted para los intelectuales, especialmente respecto a la construcción de Europa?

P.B.: Deseo que los escritores, los artistas, los filósofos y los sabios, puedan hacerse entender directamente en todos los dominios de la vida pública en que tienen su competencia. Creo que todo el mundo podría ganar mucho con la lógica de la vida intelectual, la de la argumentación y de la refutación, extendida a la vida pública. Sin embargo, hoy, es la lógica de La política, la denuncia y la difamación, de la sloganización y de la falsificación del pensamiento del adversario, que se extiende sobre la vida intelectual. Sería muy bueno que los "creadores" se ocuparan algunas veces del servicio público y, por qué no, otras veces de la salud pública.

Para pasar a la escala europea, sólo falta elevarse a un grado superior de la universalización, marcar una etapa del camino hacia el Estado universal que incluso a través de los esfuerzos de los intelectuales, está lejos de realizarse. No ganaríamos gran cosa si el eurocentrismo sustituyera a los nacionalismos heridos de las viejas naciones imperiales. En un momento en que las grandes utopías del siglo XIX han mostrado toda su perversión, es urgente crear las condiciones para el trabajo colectivo de reconstrucción de un universo de ideas realistas, capaces de movilizar las voluntades sin mistificar las conciencias.

\footnotetext{
${ }^{41}$ P. Vidal-Naquet, “Les Juifs, la mémoire et le présent”, La Découverte, tome I, Paris 1981, tome II,1991. 